EESTI NSV TEADUSTE AKADEEMIA TOIMETISED. 20. KÖIDE

KEEMIA * GEOLOOGIA. 1971, NR. 2

ИЗВЕСТИЯ АКАДЕМИИ НАУК ЭСТОНСКОИ ССР. ТОМ 20

Химия * ГЕОЛогия. 1971, № 2

удК $552.5: 549(470): 551.834$

B. КУРШС

\title{
ОСОБЕННОСТИ ФОРМИРОВАНИЯ МИНЕРАЛЬНОИ АССОЦИАЦИИ ЖИВЕТСКИХ И НИЖНЕФРАНСКИХ ТЕРРИГЕННЫХ ТОЛЩ ГЛАВНОГО ДЕВОНСКОГО ПОЛЯ
}

Изучению состава терригенных пограничных толщ среднего и верхнего девона посвящено много работ, большинство которых ставилось с целью корреляции разрезов. Основное внимание при этом было уделено изучению минеральной ассоциации песчаников, а распределение глинистых минералов освещалось слабее. Хотя проблема корреляции является сложной и до сих пор еще не решена, исследования прежних лет устано'вили ряд интересных особенностей изменения состава песчаников. Так, в центральной части Главного девонского поля обнаружено резкое увеличение снизу вверх количества устойчивых минералов за счет убывания нестойких компонентов (возрастание зрелости). Это объясняется в основном многократным перемывом осадков (Лиепиньш, 1963; Лауенкрапч, 1963). Не отрицая роли переработки и переотложения более древних осадочных толщ, Х. Вийдинг отмечает, что при формировании минерального состава большое значение имеет постепенное вскрытие эрозией все более глубоких горизонтов архейских пород, сложенных гнейсами и кристаллическими сланцами. Поэтому в верхних слоях наблюдается увеличение количества типичных метаморфических минералов - ставролита и дистена (Вийдинг, 1964).

Иного мнения о причинах изменения минеральной ассоциации девонских терригенных отложений Латвии придерживаются В. Казаринов и др. (1969), объясняющие низкое содержание нестойких компонентов в гауйских и аматских слоях формированием этих отложений на трансгрессивных этапах развития территории в значительной мере за счет переотложенных продуктов коры выветривания.

О наличии региональных изменений состава девонских терригенных толщ упоминается в работах Э. Лауенкрапч (1963), В. Василяускаса (1964) и Х. Вийдинга (1964). На основе большого фактического материала геологического картирования и результатов дополнительного опробования наличие существенных изменений в составе девонских песчаников на территории Латвии доказывается Е. Чуриловой (1968). Эти изменения объясняются непостоянством направления сноса обломочного материала. Возрастание количества малоустойчивых минералов связывается с увеличением роли терригенного материала, поступающего с юговостока и юго-запада. Отмечается также определенное значение (при формировании минеральной ассоциации песчаников) различий в условиях накопления осадков. Так, увеличение количества циркона и рутила объясняется накоплением песчаников в пляжевой зоне, где существовали 
приливно-отливные течения (Чурилова, 1968). Аномально высокое содержание граната в тяжелой фракции гауйских слоев на территории Западной Јіатвии, согласно И. Поливко (1968), связано с аллювиально-дельтовыми условиями накопления этих отложений.

Для оценки роли основных факторов, которые участвовали в формировании состава изучаемых толщ, необходимы надежные данные э направлении сноса обломочного материала. Так как обнаженность девонских отложений в целом удовлетворительна и широко распространены мульдосбразные косослоистые текстуры, характерные для водного поступательного движения * осадка (Смирнов, 1966), такие данные могут быть лолучены путем замера элементов залегания косых слойков. Наиболее благоприятны условия для изучения гауйских слоев, так как выходы их размещены на более широкой территории, в том числе в Центральной Литве и юго-восточной части Латвии. Результаты замеров,

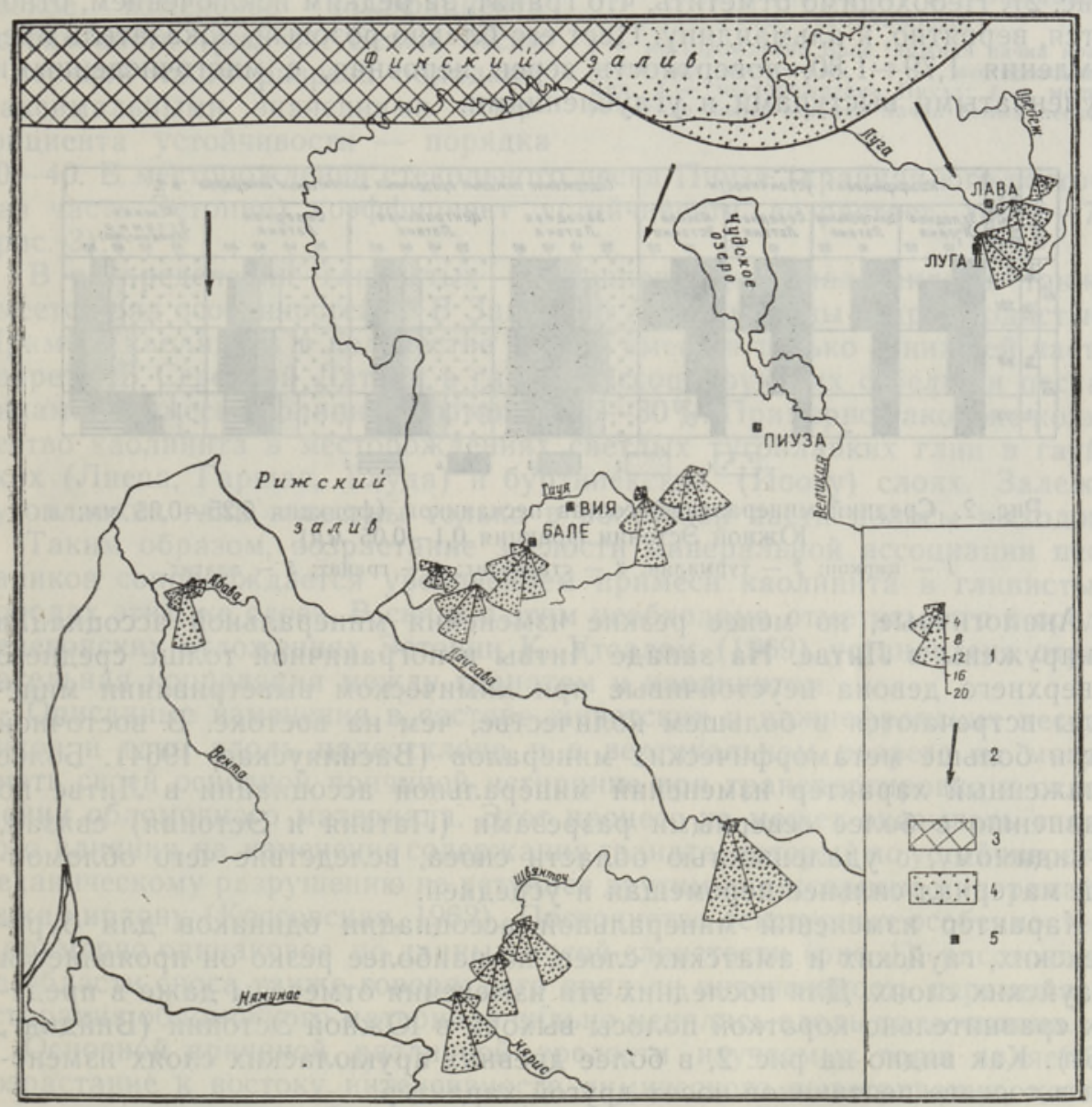

Рис. 1. Направление сноса обломочного материала в гауйское время по данным изучения косой слоистости.

1 - диаграмма-роза направлений падения косых слойков, длина радиуса сегментов соответствует количеству замеров; 2 - направление сноса обломочного материала: 3 - область, поставляющая слаборазложенный обломочный материал; 4 - область развития каолинитовой коры выветривания; 5 - карьеры стекольных песков.

* Для уточнения характера палеотечений (рекн, морские донные течения) требуется специальное изучение.

5 ENSV TA Toimetised $\mathrm{K}^{*} \mathrm{G}-2 ! 971$ 
которые изображены на рис. 1, свидетельствуют в основном о субмеридиональном, с севера на юг, направлении потоков в гауйское время. В восточной части Главного девонского поля, включая Северную Латвию и Южную Эстонию, намечается веерообразное размещение палеотечений, по конфигурации которых можно судить, что область сноса находилась, по-видимому, недалеко - южнее Фннского залива (рис. 1). В центральной части Литвы сохряняется южное направление палеотечений, поэтому продукты размыва Белорусского выступа вряд ли оказывали заметное влияние на состав гауйских слоев.

Вдоль палеосклона, с юга-запада на северо-восток, наблюдаются отчетливые изменения в составе песчаников и глин. Так, в Западной Латвии среди тяжелых аллотигенных прозрачных минералов преобладает гранат, а циркон занимает второе место. В Центральной и Северной Латвии и особенно в Южной Эстонии количество граната сильно уменьшается, а цирксна, турмалина и ставролита - увеличивается (рис. 2). Необходимо отметить, что гранат, за редким исключением, относится, вероятно, к альмандину. Цвет его бледно-розовый, показатель преломления $1,79-1,80$, поверхность зерен неровная, с многочисленными ступенчатыми выступами и углублениями.

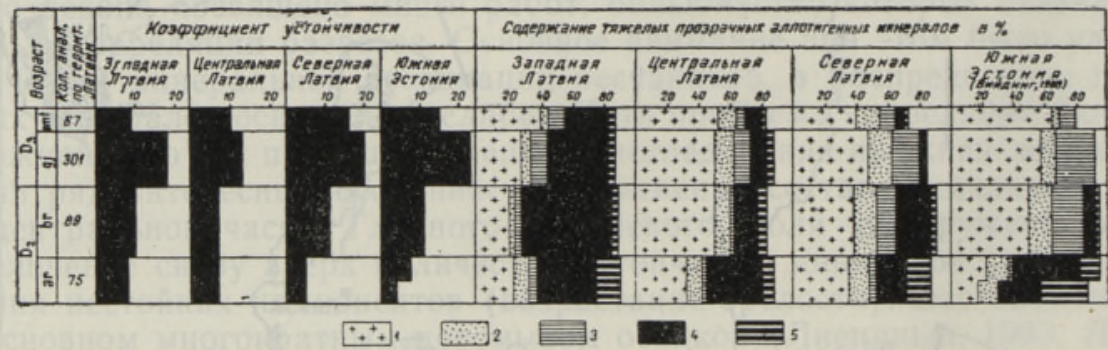

Рнс. 2. Средний минеральный состав песчаников (фракция $0,25-0,05$ мм; в Южной Әстонии фракция $0,1-0,05$ мм).

1 - циркон; 2 - турмалин; 3 - ставролит; 4 - гранат; 5 - апатит.

Аналогичные, но менее резкие изменения минеральной ассоциации об́наружены в Литве. На западе Литвы в пограничной толще среднего. и верхнего девона неустойчивые при химическом выветривании минералы встречаются в большем количестве, чем на востоке. В восточной части больше метаморфических минералов (Василяускас, 1964). Более сглаженный характер изменений минеральной ассоциации в Литве по сравнению с более северными разрезами (Латвия и Эстония) свлзан, по-видимому, с удаленностью области сноса, вследствие чего обломочный материал сильнее перемешан и усреднен.

Характер изменений минеральной ассоциации одинаков для буртниекских, гауйских и аматских слоев, но наиболее резко он проявляется в гауйских слоях. Для последних эти изменения отмечены даже в предєлах сравнительно короткой полосы выхода в Южной Әстонии (Вийдинг, 1964). Как видно на рис. 2, в более древних арукюласких слоях изменения в составе песчаников носят другой характер.

Простым и эффективным методом для характеристики зрелости минеральной ассоциации изучаемых толщ является определение отношения содержания кварца к полевому шпату (коэффициент устойчивости). Однако в связи с повсеместной регенерацией полевого шпата анализ широкой $(0,25-0,05$ мм) и тем более мелкой фракции, как это видно на рис. 3 , должен быть заменен изучением узкой фракции крупнозернистого песка $(0,315-0,2$ мм). Анализы этой фракции из двух картировоч- 
ных скважин подтверждают уже заметный на рис. 2 факт, что более западные разрезы (скв. 8, Валтайки) характеризуются пониженными значениями коэффициента устойчивости по сравнению с разрезами Северной Латвии (скв. 10, Звартава). По данным последней скважины, также как и скв. 339, пробуренной в месторождении стекольного песка Бале, вытекает, что на границе красноцветных песчаников нижней части гауйских слоев и перекрывающих их белых стекольных и формовочных песков происходит резкое изменение коэффициента устоӥчивости (рис. 4). Белые пески в верхней части разреза обладают максимальными значениями коэффициента устойчивости - порядка

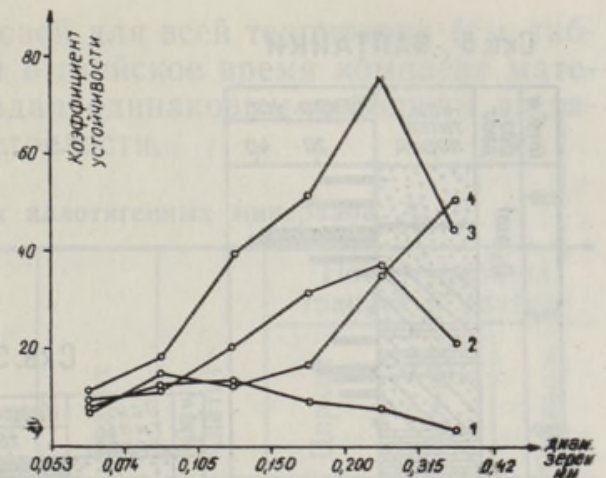

Рис. 3. Зависимость между диаметром зерен стекольных песков и коэффициентом устойчивости.

$t$ - месторожденне Бале, нижняя пачка красноцветных песчаников; 2 - месторожденне Вия: 3 - месторождение Пиуза: $4-$ месторождение Бале, верхняя пачка белых песков. 30-40. В месторождении стекольного песка Пиуза (крайняя юго-восточная часть Эстонии) коэффициент устойчивости возрастает до 50-75 (рис. 3).

В распределении глинистых минералов вдоль палеосклона также имеется ряд особенностей.** В Западной Латвии глины гидрослюдистые. Примесь каолинита в количестве до $5 \%$ имеется только в нижней части разреза. В Северной Латвии в глинах, ассоциирующих с белыми песчаниками, примесь каолинита достигает 25-30\%. Примерно такое жеколичество каолинита в месторождениях светлых тугоплавких глин в гауйских (Лиепа, Гаршас, Глуда) и буртниекских (Ноозу) слоях. Залежи тугоплавких глин известны только в восточной части полосы выходов.

Таким образом, возрастание зрелости минеральной ассоциации песчаников сопровождается увеличением примеси каолинита в глинистых породах этих же слоев. В связи с этим необходимо отметить, что в среднедевонских отложениях Эстонии К. Утсалом (1969) установлена отрнцательная корреляция между гранатом и каолинитом.

Описанные изменения в сэставе живетских и нижнефранских песчаников и глин вдоль палеосклона и в вертикальном разрезе не могут иметь своей основной причиной истирание при транспортировке и отложении обломочного материала. Этот процесс не может оказывать сильного влияния на изменение содержания граната, который по устойчивости механическому разрушению не уступает другим акцессорным минералам. даже циркону (Коссовская, 1962). Постоянство текстурных особенностей и примерно одинаковое по данным косой слоистости (рис. 1) расстояние дс области сноса также говорят, что вряд ли интенсивность перемыва и истирания обломочного материала сильно менялась вдоль палеосклона.

Основной причиной различной зрелости изучаемых толщ является возрастание к востоку интенсивности химического выветривания, которое разрушает полевой шпат, гранат и апатит. Возникает ассоциация весьма устойчивых минералов (кварц, циркон, турмалин, ставролит, дистен) в песчаных породах и увеличивается роль каолинита в глинах. Расчеты показывают, что в случае полніого разрушення граната и апатита ассоциация оставшихся акцессорных минералов в песчаниках гауй-

** Состав глинистых пород изучался А. Стинкуле на дифрактометре УРС-50 ИМ химического факультета Рижского политехнчческого института. 
СКв.8, ВАЛТฺАЙКИ

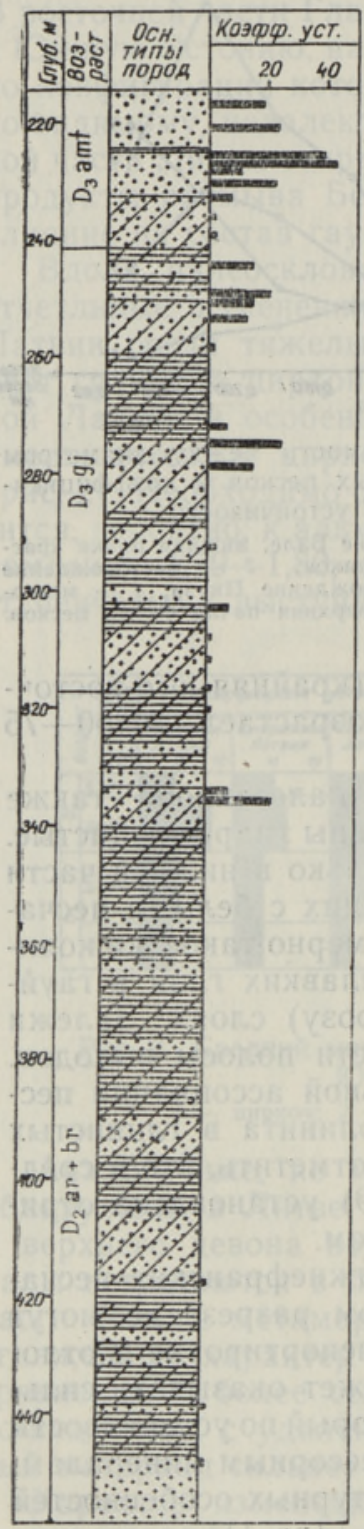

СКв. 339, БАЛЕ
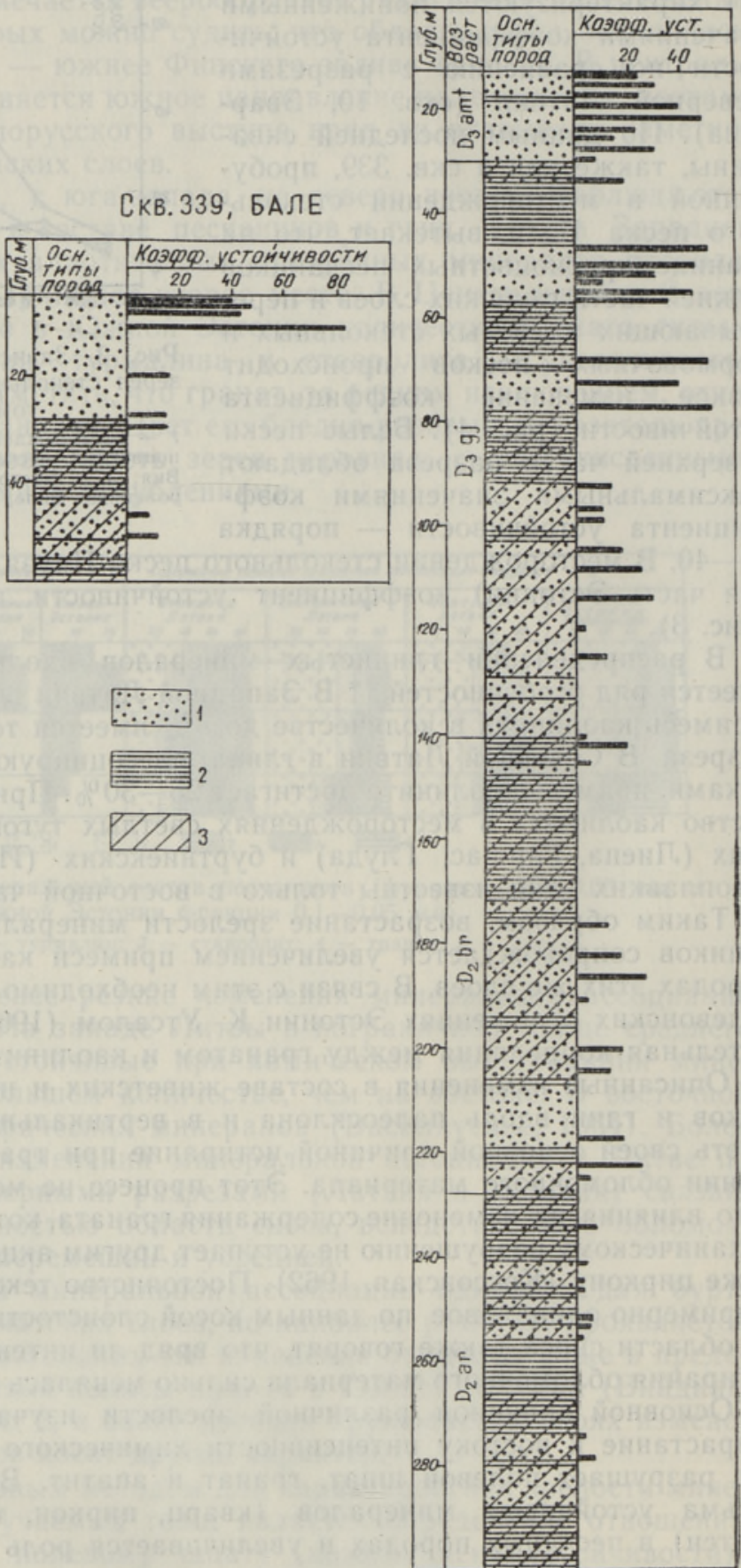

Рис. 4. Разрезы пограничных слоев среднего и верхнего девона Латвии с данными об изменениях коэффициента устойчивости.

1 - песчаники; 2 - алевролиты и глины; 3 - красноцветность отложепий 
ских слоев стала бы примерно одинаковой для всей территории (см. таблицу). Поэтому вскрываемый эрозией в гауйское время комплекс материнских пород в области сноса обладал одинаковым исходным составом, отличаясь лишь по степени выветрелости.

Содержание тяжелых прозрачных аллотигенных минералов, \%

\begin{tabular}{l|c|c|c|c|c|c|c|c}
\hline & & & & & & \multicolumn{3}{|c}{ После удаления } \\
граната и апатита
\end{tabular}

В связи с постепенным возрастанием зрелости отложений в восточном направлении большой интерес представляет разрез девонских терригенных толщ в крайней восточной части Главного девонского поля по рр. Луга и Оредеж. Среди фаунистически охарактеризованных лужских (арукюласких в центральной части Главного девонского поля) и старицских (аматских) слоев здесь залегает толща немых белых песчаников - ящерские слои (Рухин, 1946; Обручев, 1951). Предполагается, что ящерские слои представляют собой кору выветривания лужских песча: ников и по возрасту относятся к среднему девону (Тихомиров, 1966).

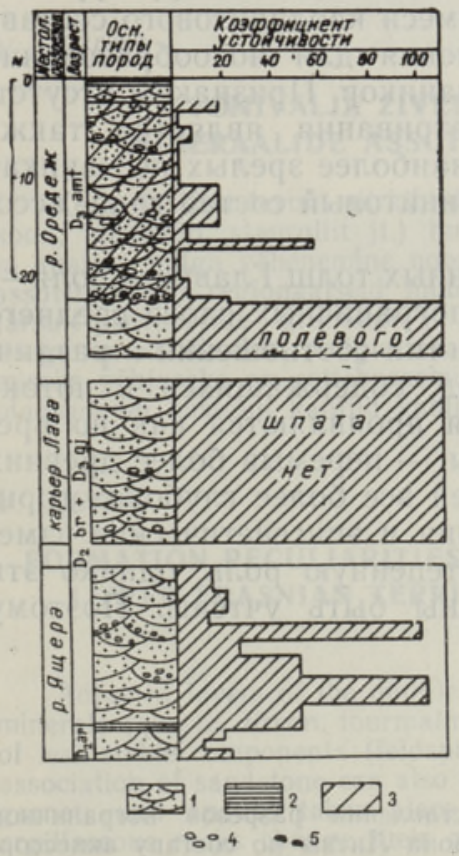

Рис. 5. Разрез погранитных слоев среднего и верхнего девона Ленинградской области с данными об изменениях коэффициента устойчивости.

1 - косослоистые песчаники; 2 глины; 3 - краснощветность отложений; 4 - катыши глины; 5 фосфориты.

Ящерские слои имеют много общих черт с белыми песчаниками Северной Латвии и Южной Эстонии - они представляют собой наиболее зрелую часть разреза терригенной толщи и содержат остатки окремнелых 
растений при полном отсутствии обломков ихтиофауны. Для минеральной ассоциации ящерских песчаников характерна высокая степень зрелости, особенно в верхней части разреза, где имеются мономинеральныє кварцевые песчаники (рис. 5). Среди тяжелых аллотигенных прозрачных минералов преобладают, по данным В. Белоусовой, циркон, турмалин, ставролит и другие устойчивые минералы. Граната очень мало, а апатита нет. В катышах глин из ящерских слоев каолинит преобладает над гидрослюдой (рис. 6).

Таким образом, региональные изменения вдоль палеосклона состава пограничных слоев среднего и верхнего девона, обусловленные усилением в восточном направлении интенсивности химического выветривания обломочного материала, достаточно отчетливо проявляются также в восточной части Главного девонского поля.

Наиболее сложным и еще недостаточно изученным является вопрос o характере химического выветривания: произошло ли выветривание материнских пород в области сноса (в таком случае изучаемые зрелые отложения состоят из продуктов перемыва кор выветривания) или же исчезновение нестойких компонентов и каолинизация пород связаны с выветриванием песчаников в приповерхностных условиях? По-видимому, более правильным является первсе предположение, так как постседиментационные изменения девонских песчаников - регенерация полевых шпатов и кварца, гидратация и каолинизация слюд и др. - охватывают всю площадь Главного девонского поля, в том числе западную часть с менее зрелыми отложениями, а также толщи большего возрастного диапазона, чем пограничные слои среднего и верхнего девона (Тамме, 1965; Василяускас, 1965). Некоторое усиление гидратации и каолинизации слюд в ящерских песчаниках связано, вероятно, с поступлением в осадок слюд с уже частично разложенной кристаллической структурой, а довольно большое количество глинистой примеси каолинитового состава (рис. 6) создало более благоприятные условия для новообразования каолинита в поровом пространстве этих песчаников. Признаком отсутствия интенсивного приповерхностного выветривания является также отчетливость косослоистых текстур даже в наиболее зрелых песчаниках верхней части ящерских слюев, а также каолинитовый состав глин, ассоциирующих с этими песчаниками.

Формирование состава девонских терригенных толщ Главного поля -процесс сложный. Основные черты состава пограничных слоев среднего и верхнего девона обусловливаются изменениями соотношения в различной степени выветрелых материнских пород, содержащихся в потоке наносных продуктов размыва. Эти различия проявляются как во времени, так и территориально. Другие факторы - перемыв более древних толщ, различный состав вскрываемых эрозией все более глубоких горизонтов материнских пород, условия отложения и эпигенетические изменения песчаников и глин - играют второстепенную роль, однако эти факторы безусловно имеют место и должны быть учтены. Поэтому их изучение нужно продолжить.

ЛН ТЕ Р АТ У РА

В асиля уска с В. М. 1964. О возможности сопоставления разрезов пограничной пестроцветной толщи среднего и верхнего девона Литвы по составу акцессорных минералов. В сб.: Вопросы стратиграфии и палеогеографии девона Прибалтики. Вильнюс.

В а с и ля уск а с В. М. 1965. Некоторые вторичные изменения пород среднего и верхнего девона Литвы. В сб.: Геология и нефтеносность палеозоя Южной Прибалтики. Вильнюс. 
В и йдинг Х. А. 1964. О литологии и минералогии песчано-алевролитовых отложений девона в Эстонской ССР. В сб.: Вопросы стратиграфии и палеогеографии девона Прибалтики. Вильнюс.

В и йд и н Г X. А. 1968. Литолого-минералогический состав и вопросы генезиса терригенных отложений девона Северной Прибалтики. В сб́.: Генезис и классификация осадочных пород. М.

К а з аринов В. П., Бгатов В.И., Гу рова Т. И., К аз ан ски й Ю. П., Будни к о в В. И. и др. 1969. Выветривание и литогенез. М.

К оссов к а я А. Г. 1962. Минералогия терригенного мезозойского комплекса Вилюйской впадины и Западного Верхоянья. Тр. Геол. ин-та АН СССР, вып. 63. М.

Л а у ен к р а п ч Э. К. 1963. Обломочные породы франского яруса верхнего девона Лат внйской ССР. В сб.: Франские отложения Латвийской ССР. Рига.

Л и епиньш П. П. 1963. Условия формирования франских отложений Прибалтнки. В сб.: Франские отложения Латвийской ССР. Рига.

О 6 ручев Дм. 1951. О границе между средним и верхним девоном в Главном поле. Докл. АН СССР, Н. сер., 28, № 5.

По ли вко И. А. 1968. Особенности осадконакопления в раннефранское время на тер. ритория Латвийской ССР. Сов. геол., № 1.

Р у и н Л. Б. 1946. Стратиграфия песчаной толщи среднего девона Лужского и Оредежского районов Ленинградской области. Науч. бюлл. ЛГУ, № 10.

С м и р но в Л. С. 1966. Новые данные изучения косослоистых текстур. Сов. геол., № 6.

Т а м е А. 1965. О некоторых диа- и эпигенетических явлениях в среднедевонских отле. жениях Эстонии. Уч. зап. Тартуск. гос. ун-та. Тр. по геол., III.

Т и хом и ров С. В. 1966. О некоторых причинах изменения экологических обстановок в франском веке к востоку от Главного девонского поля. В кн.: Организм и среда в геологическом прошлом. М.

У гсал К. Р. 1969. Рентгенографическое исследование глинистых минералов среднедевонских отложений Эстонии. Автореф. дисс. канд. геол.-мин. н. Тарту.

ч урилов а Е. 1968. Минералогическая корреляция верхнефранских отложений Латвии. В кн.: Материалы пятой конференции геологов Прибалтики и Белоруссин. Вильнюс.

Всесоюзный научно-исследовательский институт морской геологии и геофизики

Поступила в редакцию $29 / \mathrm{IX} 1970$

\section{KURSS}

\section{PEADEVONIVÄLJA ZIVEE JA ALAMFRAANI TERRIGEENSETE SETETE MINERAALIDE ASSOTSIATSIOONI KUJUNEMISE ISEÄRASUSED}

Kesk- ja ülemdevoni piirkihtides on kindlaks tehtud püsivate mineraalide (kvarts, tsirkoon, turmaliin, stauroliit jt.) hulga suurenemine ja vähempüsivate (päevakivi, granaat ja apatiit) hulga vähenemine nooremate setete suunas. Samuti on täheldatud mineraalide assotsiatsiooni regionaalseid muutusi liivakivides. Piki kilbi nōlva väheneb ida suunas järsult päevakivide-, granaadi- ja apatiidisisaldus. Samal ajal lähevad hüdrovilgulise koostisega savid üle hüdrovilgulis kaoliniitseteks. Mineraalide assotsiatsiooni muutuste peamiseks pōhjuseks on settebasseini kantud lähtekivimite erinev murenemisaste. Balti kilbi idaosast on basseini kantud kaoliniitse murenemiskoorikti materjali.

\section{KURSS}

\section{FORMATION PECULIARITIES IN MINERAL ASSOCIATIONS OF GIVETIAN AND LOWER FRASNIAN TERRIGENOUS STRATA BELONGING TO THE MAIN DEVONIAN FIELD}

Adjacent layers of the middle and upper Devonian show an upward increase of stab!e minerals (quartz, zircon, tourmalin, staurolite, etc.) quantity, and a corresponding decrease of less stable components (feldspar, garnet and apatite). Regional changes in the mineial association of sandstone can also be detected. A drastic decrease in the content of feldspar, garnet, and apatite takes place along the palaeoslope in the eastern direction. The argillaceous rocks change their composition from hydromical to hydromical/kaolinitic, in the same direction. The main reason for these changes in the mineral association of the terrigenous strata belonging to the Main Devonian Field is the supply to the sedimentation basin from mother rocks weathered to various degrees. Washout products from the kaolinitic crust of weathering were transported by palaeocurrents from the eastern part of the Baltic shield, 